\title{
Parameter sensitivity and economic analyses of an interchange-fracture enhanced geothermal system
}

\author{
Guojun $\mathrm{Yu}^{1 \oplus *}$, Cong Liu ${ }^{1}$, Lizhi Zhang ${ }^{1}$, Lichao Fang ${ }^{2}$ \\ ${ }^{1}$ Merchant Marine college, Shanghai Maritime University, Shanghai 201306, P. R. China \\ ${ }^{2}$ Department of Mechanical Engineering, Northwestern University, Evanston IL 60208, USA
}

\section{Keywords:}

Enhanced geothermal system thermal extraction performance parameter sensitivity analysis numerical simulation

Cited as:

Yu, G., Liu, C., Zhang, L., Fang, L. Parameter sensitivity and economic analyses of an interchange-fracture enhanced geothermal system. Advances in Geo-Energy Research, 2021, 5(2):

166-180, doi: 10.46690/ager.2021.02.06

\begin{abstract}
:
Previous research has shown that interchange-fracture enhanced geothermal systems show desirable heat extraction performance. However, their parameter sensitivity has not been systematically investigated. In this study, a three-dimensional, unsteady flow and heat transfer model for an enhanced geothermal system with an interchange-fracture structure was established. The influences of pivotal parameters, including stimulated reservoir volume permeability, fracture spacing, fracture aperture, and injection flow rate on the thermal extraction performance of the interchange-fracture enhanced geothermal system were systematically researched. In addition, the economics of this system were evaluated. The results show that the heat extraction performance of the interchange-fracture system is significantly affected by a change of stimulated reservoir volume permeability and injection flow rate. Increasing permeability reduces electricity costs and improves economic income, while increasing the injection flow rate increases output power but hinders the long-term running stability of the system. Our research provides guidance for the optimal design of an interchange-fracture enhanced geothermal system.
\end{abstract}

\section{Introduction}

As a clean and sustainable energy source, geothermal energy has attracted increasing attention (Ding and Wang, 2018; Abdel-Salam and Zaidi, 2021; Habibzadeh-Bigdarvish et al., 2021). Compared with solar energy and wind energy, geothermal energy possesses many advantages, including being unaffected by weather, stable performance, small ecological effects, abundant reserves, and high thermal efficiency (Li et al., 2015). A hot dry rock (HDR) source with a temperature of over $150{ }^{\circ} \mathrm{C}$ is a deep, geothermal energy source which has broad development prospects (Zhao et al., 2015). The enhanced geothermal system (EGS) is a highefficiency method for developing and utilizing HDR sources. Since the first test, carried out by the Los Alamos National Laboratory in the United States in 1972 (Pollack and Mukerji, 2019), many countries in the world have devoted significant resources to the research of EGS (Zaigham and Nayyar, 2010; Bujakowski et al., 2015; Anyim and Gan, 2020; Zhou et al., 2020). The fracture-well system constitutes the preferential flow conduits and heat exchange zones for the underground heat transfer system of EGS, and the rationality of its spatial arrangement has a great impact on heat-mining performance.

To achieve efficient exploitation of HDR geothermal energy, various well-fracture systems for EGS have been proposed. These include the single horizontal well-fracture system (Wang and $\mathrm{Wu}, 2019$ ), double horizontal well-fracture system (Xu et al., 2018), vertical well-fracture system (Lei et al., 2020), multi-well-fracture system (Ma et al., 2020), multilateral well-fracture system (Song et al., 2018), and Ushaped closed loop system (Sun et al., 2018). The effects of geological parameters, geometrical parameters, and operational parameters on EGS thermal recovery capability have also been investigated.

Wang et al. (2020) proposed a new type of single, horizontal well-fractured EGS, and studied the effects of injection flow rate, injection well length, injection-production well distance, production well length, and initial reservoir temperature on system heat mining. Their results indicate that the production temperature of the system is most sensitive to the reservoir temperature, followed by the injection-production well spacing 
and injection flow rate, and is least sensitive to other factors. Zeng et al. (2013) studied the thermal extraction of a double horizontal well-fracture system based on the actual geological data of the Desert Peak geothermal field. Their results show that the output thermal power of the system depends mainly on the water production rate and water injection temperature, while flow impedance depends mainly on stimulated reservoir permeability. Lei et al. (2019) studied the effects of the injection rate, well spacing, and injection temperature on a vertical well-fracture system based on the geological conditions of the Qiabuqia geothermal field in northwest China. The results also show that the injection flow rate and injection temperature have a great influence on impedance and output power. The larger the flow rate, the larger the impedance; and the larger the injection temperature, the smaller the output thermal power.

In addition to the traditional well-fracture systems mentioned above, some special cases have also been investigated. Aliyu and Archer (2021) established a three-dimensional thermo-hydro-mechanical model of a double-tilted wellfracture system and studied the effects of fracture number, fracture spacing, and other parameters on heat mining capacity. Their results show that increasing the number of fractures contributes to a higher production temperature, while decreasing the fracture spacing leads to faster production temperature depletion. Ma et al. (2020) established a two-dimensional (2D) model for a multi-well-fracture system and studied the effects of different well layouts and fracture schemes on heat recovery. The results show that there is a negative correlation between thermal output power and fracture aperture, and that a moderate increase in the number of fractures can improve heat recovery, while an excessive increase will aggravate the thermal interference between fractures. Song et al. (2018) established a mathematical model for a multilateral wellfracture system, and Shi et al. (2018) further studied the parameter sensitivity of the system using supercritical $\mathrm{CO}_{2}$ as a working medium. Their results show that increasing the number and length of lateral wells can improve the heatmining performance of the system, while the influence of lateral well diameter on heat mining is insignificant.

Besides studying geothermal systems with fracture structures, some researchers have also studied closed-loop systems without fractures. Liao et al. (2021) established a threedimensional model of a multi-U-shaped well system without fractures and studied the influence of geothermal gradient, injection rate, horizontal well interval length, and other factors on the heat recovery capacity of the system. They also carried out an economic analysis. It was found that the heat generation of the system first increases and then decreases with a decrease of the injection rate. Thus, there is an optimal injection rate. When the injection rate exceeds the optimal injection rate, the cost of per-unit generation increases significantly with the increase of the injection rate. Wang et al. (2021) proposed a novel, multilateral-well, coaxial closed-loop geothermal system and analyzed the effects of the injection flow rate, number of side wells, wellbore size, reservoir temperature, and other parameters on the heat generation of the system. Their results indicate that a small lateral well diameter is more conducive to heat extraction. Increasing the injection flow rate can increase the output thermal power but will reduce the production temperature.

In summary, the heat extraction process of EGS is a complex multi-field coupling process, which is affected by lots of parameters (Chen et al., 2019). However, different geothermal systems have different sensitivities to various parameters. Therefore, targeted parameter sensitivity analysis is needed for different systems. In our previous work, an enhanced geothermal system with two sets of a $90^{\circ}$ interchange-fracture structure was proposed, but the influence of key parameters on its heat recovery performance was not analyzed. In this paper, the influence of different factors on the performance of the proposed $90^{\circ}$ interchange-fracture EGS is systematically studied.

In this present research, a three-dimensional unsteady flow and heat transfer model of the $90^{\circ}$ interchange-fracture EGS is established. The effects of stimulated reservoir volume (SRV) permeability, fracture spacing, fracture aperture, injection flow rate, and well spacing on the heat mining of the system are studied, and an economic analysis is carried out. This study can guide the formulation of a fracturing scheme of the $90^{\circ}$ interchange-fracture EGS at the macro level, and provides an important theoretical basis for the development and utilization of hot dry rock resources.

\section{Physical descriptions}

\subsection{Physical process}

Fracture propagation is influented by stress anisotropy, hydraulic fracturing strategy, rock properties, and drilling techniques. The propagation of fracture can be controlled by directional hydraulic fracturing technology (Bai et al., 2020). Combined with directional drilling technology and directional fracturing technology, EGS with a $90^{\circ}$ interchange fracture structure can be obtained; its working principle is shown in Fig. 1(a). Unlike conventional, double-horizontal well EGS, there is a crossing-angle of $90^{\circ}$ between the injection and the production wells. Each of the two wells has a set of fractures, which are not connected. The vertical spacing between the fracture groups is approximately $1 \mathrm{~m}$. This is called an "unfractured thin layer". The details within the stimulated reservoir volume are shown in Fig. 1(b). When the system is running, the low-temperature fluid enters the reservoir through the injection well and flows through the upper fractures, the unfractured thin layer and the lower fracture successively. After a thorough heat exchange with the hot dry rock, the hightemperature working medium returns to the geothermal power station through the production well to generate electricity, and is then again injected into the injection well, completing a working cycle.

\subsection{Physical model}

In this current research, we established a three-dimensional discrete fracture network model for a $90^{\circ}$ interchange-fracture EGS after referring to existing studies (Sun et al., 2017; Ijeje, 2019; Gong et al., 2020; Ma et al., 2020; Bongole et al., 2021), as shown in Fig. 2. This is a conceptual model as there is no engineering precedent for a $90^{\circ}$ interchange fracture EGS. The 


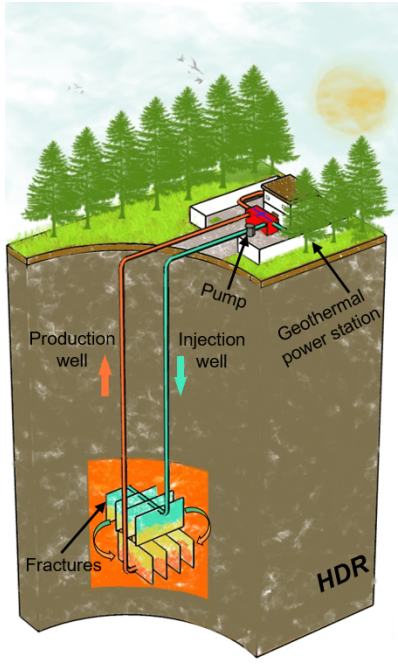

(a)

Fig. 1. Schematic of heat mining for the interchange-fracture EGS.

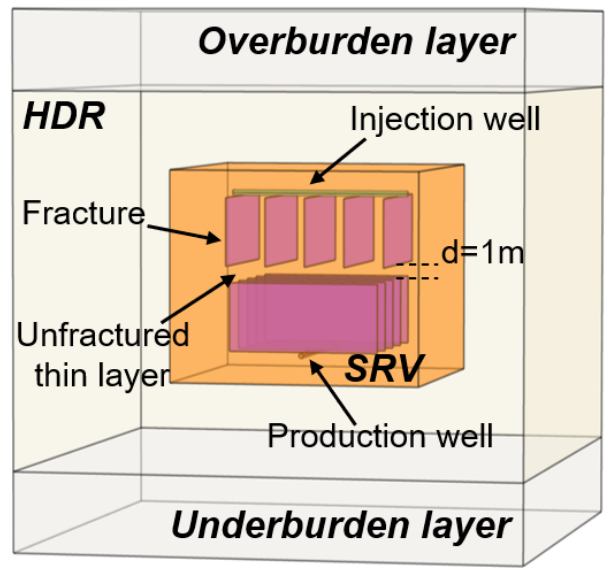

Fig. 2. Schematic of the physical model.

computational domain is a cube with sides of $1500 \mathrm{~m}$ located at a depth of $4250 \sim 5750 \mathrm{~m}$ underground, composed of an overburden layer, the HDR, the SRV, and an underburden layer. Both the overburden and underburden layers are $100 \mathrm{~m}$ thick, and the SRV is at the center of the HDR with a dimension of $500 \mathrm{~m} \times 500 \mathrm{~m} \times 400 \mathrm{~m}$, including one injection well, one production well, and 10 fractures distributed equally into two groups. There is an intersection angle of $90^{\circ}$ between the injection well and the production well, and the well length is $360 \mathrm{~m}$. The width and height of the fracture are $300 \mathrm{~m}$ and $149.5 \mathrm{~m}$, respectively. As for the reference case used for comparison, the fracture spacing is $80 \mathrm{~m}$ and the vertical well spacing is $300 \mathrm{~m}$. The geological parameters are referenced mainly from the studies of Song et al. (2018) and Ma et al. (2020). The key geometric and geological parameters are listed in Tables 1 and 2, respectively. In addition, since the objective of this paper is to compare the influence of different geological and operating parameters on heat mining performance, the variable parameters used in different cases are listed in Table 3.

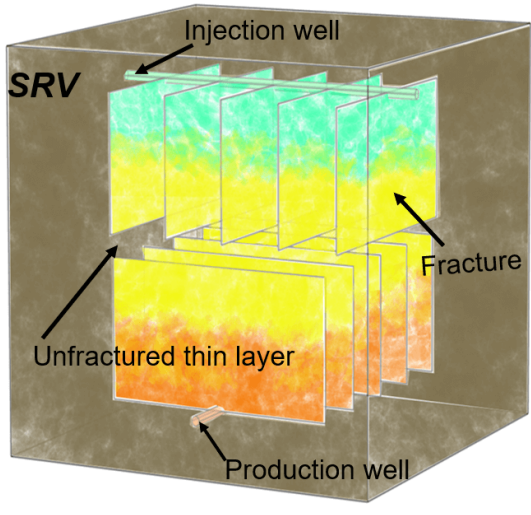

(b)

\section{Computational model}

Based on existing research (Song et al., 2018; Gong et al., 2020; Ma et al., 2020), the following assumptions for the underground system were made: (1) we ignore the elasticity of the rock, and thus the overburden layer, the underburden layer, the SRV, and the HDR are considered as homogeneous and isotropic continuous porous media; (2) compared with the SRV, the permeability of the overburden and the underburden layer is very small, thus they are regarded as impermeable boundaries; (3) there is a local thermal balance between the solid rock and the working fluid; (4) the effect of proppant on the fracture is not considered, and the fracture is assumed to be completely open; (5) the fracturing fluid is water, which does not evaporate under running conditions, and so the reservoir is initially filled with saturated liquid water, and the working medium flow in the rock and fractures follows Darcy's law. In addition, the density and viscosity of water are obtained from the work of Holzbecher (1998):

Table 1. The geometrical parameters of the simulation model.

\begin{tabular}{ll}
\hline Description & Value \\
\hline Computational domain size & $1500 \mathrm{~m} \times 1500 \mathrm{~m} \times 1500 \mathrm{~m}$ \\
Computational depth & $-4250 \sim-5750 \mathrm{~m}$ \\
SRV size & $500 \mathrm{~m} \times 500 \mathrm{~m} \times 400 \mathrm{~m}$ \\
SRV depth & $-4800 \sim-5200 \mathrm{~m}$ \\
Well diameter & $0.1 \mathrm{~m}$ \\
Well length & $360 \mathrm{~m}$ \\
Fracture aperture & $1 \mathrm{~mm}$ \\
Fracture width & $300 \mathrm{~m}$ \\
Fracture height & $149.5 \mathrm{~m}$ \\
Fracture spacing & $80 \mathrm{~m}$ \\
Well spacing & $300 \mathrm{~m}$ \\
\hline
\end{tabular}


Table 2. The geological parameters of the simulation model.

\begin{tabular}{llllll}
\hline Description & Overburden layer & HDR layer & SRV & Underburden layer & Fracture \\
\hline Grain density $\left(\mathrm{kg} / \mathrm{m}^{3}\right)$ & 2600 & 2700 & 2700 & 2800 & 2000 \\
Heat conductivity $(\mathrm{W} /(\mathrm{m} \cdot \mathrm{K}))$ & 2 & 2.8 & 2.8 & 2 & 2.8 \\
Heat capacity $(\mathrm{J} / \mathrm{kg} \cdot \mathrm{K}))$ & 1000 & 1000 & 1000 & 1000 & 850 \\
Porosity $(\%)$ & 1 & 8 & 15 & 1 & 100 \\
Permeability $(\mathrm{mD})$ & 0.001 & 0.05 & 1 & 0.001 & 50000 \\
\hline
\end{tabular}

Table 3. The variable parameters used in different cases.

\begin{tabular}{|c|c|c|c|c|c|}
\hline Description & SRV permeability $(\mathrm{mD})$ & Fracture aperture $(\mathrm{mm})$ & Fracture spacing $(\mathrm{m})$ & Injection flow rate $(\mathrm{kg} / \mathrm{s})$ & Well spacing $(\mathrm{m})$ \\
\hline Base & 1.0 & 1.0 & 80 & 30 & - \\
\hline Case 1 & 0.5 & - & - & - & - \\
\hline Case 2 & 2.0 & - & - & - & - \\
\hline Case 3 & 5.0 & - & - & - & - \\
\hline Case 4 & - & 0.5 & - & - & - \\
\hline Case 5 & - & 1.5 & - & - & - \\
\hline Case 6 & - & 2.0 & - & - & - \\
\hline Case 7 & - & - & 50 & - & - \\
\hline Case 8 & - & - & 60 & - & - \\
\hline Case 9 & - & - & 70 & - & - \\
\hline Case 10 & - & - & - & 20 & - \\
\hline Case 11 & - & - & - & 40 & - \\
\hline Case 12 & - & - & - & 50 & - \\
\hline Case 13 & - & - & - & - & 240 \\
\hline Case 14 & - & - & - & - & 270 \\
\hline Case 15 & - & - & - & - & 330 \\
\hline
\end{tabular}

$$
\begin{gathered}
\rho_{w}=\left\{\begin{array}{l}
996.9\left[1-3.17 \times 10^{-4}(T-298.15)\right. \\
\left.-2.56 \times 10^{-6}(T-298.15)^{2}\right] \\
\text { for } 298.15 \mathrm{~K}<T<373.15 \mathrm{~K} \\
1758.4-4.8434 \times 10^{-6} T+1.0907 \times 10^{-8} T^{2} \\
-9.8467 \times 10^{-12} T^{3} \\
\text { for } 373.15 \mathrm{~K}<T<593.15 \mathrm{~K}
\end{array}\right. \\
\mu_{f}=\left\{\begin{array}{l}
10^{-3}[1+0.015512(T-293.15)]^{-1.572} \\
\text { for } 273.15 \mathrm{~K}<T<373.15 \mathrm{~K} \\
2.414 \times 10^{\frac{247.8}{T-140}-5} \\
\text { for } 373.15 \mathrm{~K}<T<593.15 \mathrm{~K}
\end{array}\right.
\end{gathered}
$$

\subsection{Governing equations}

The flow of water in the rock matrix follows Darcy's law, which is described by the mass conservation equation:

$$
\frac{\partial\left(\rho_{w} \varphi_{s}\right)}{\partial t}+\nabla \cdot\left(\rho_{w} \boldsymbol{u}_{s}\right)=-Q_{f}
$$

where $\rho_{w}$ is the water density, $\varphi_{s}$ is the rock porosity, $t$ is the time, and $Q_{f}$ is the mass exchange between rock and fracture. $\boldsymbol{u}_{\boldsymbol{s}}$ is the Darcy velocity, which can be derived by the momentum equation:

$$
u_{s}=-\frac{k_{s}}{\mu_{f}}\left(\nabla p+\rho_{w} g \nabla z\right)
$$

where $k_{s}$ is the rock permeability, $\mu_{f}$ is the viscosity, $p$ is the water pressure, $\rho_{w} g \nabla z$ is the gravity term, and $g$ and $z$ are the gravity acceleration and vertical coordinate, respectively.

The mass conservation equation in the discrete fracture network is:

$$
d_{f} \frac{\partial\left(\rho_{w} \varphi_{f}\right)}{\partial t}+\nabla_{T} \cdot\left(d_{f} \rho_{w} \boldsymbol{u}_{f}\right)=d_{f} Q_{f}
$$

where $d_{f}$ is the fracture aperture, $\varphi_{f}$ is the fracture porosity, and $\nabla_{T}$ is the gradient operator on the fracture's tangential plane. $\boldsymbol{u}_{\boldsymbol{f}}$ represents the Darcy velocity in the fractures, which is expressed as:

$$
\boldsymbol{u}_{\boldsymbol{f}}=-\frac{k_{f}}{\mu_{f}}\left(\nabla_{T} p+\rho_{w} g \nabla_{T} z\right)
$$

where $k_{f}$ is the fracture permeability. 
For the heat exchange process, based on the assumption of a local heat balance, the energy conservation in the reservoir rock is given by Eq. (7):

$$
\left(\rho c_{p}\right)_{e f f} \frac{\partial T}{\partial t}+\rho_{w} c_{p, w} u_{s} \cdot \nabla T-\nabla \cdot\left(\lambda_{e f f} \nabla T\right)=-Q_{f, E}
$$

where $T$ is the temperature of the rock, $c_{p, w}$ is the heat capacity of the water, $\left(\rho c_{p}\right)_{e f f}$ is the effective volume heat capacity, and $\lambda_{e f f}$ is the effective thermal conductivity, which can be described by the following equations:

$$
\begin{gathered}
\left(\rho c_{p}\right)_{e f f}=(1-\varphi) \rho c_{p}+\varphi \rho_{w} c_{p, w} \\
\lambda_{\text {eff }}=(1-\varphi) \lambda+\varphi \lambda_{w}
\end{gathered}
$$

where $\rho$ is the density of the solid part, $\rho_{w}$ is the density of water, $c_{p}$ is the heat capacity of solid part, and $\lambda$ and $\lambda_{w}$ are the thermal conductivity of solid part and water, respectively.

The energy conservation equation in the fractures is described as follows:

$$
\begin{aligned}
& d_{f}\left(\rho c_{p}\right)_{e f f} \frac{\partial T}{\partial t}+d_{f} \rho_{w} c_{p, w} u_{f} \cdot \nabla_{T} T-\nabla_{T} \cdot\left(d_{f} \lambda_{e f f} \nabla T\right) \\
& =d_{f} Q_{f, E}
\end{aligned}
$$

where $Q_{f, E}$ is the heat exchange between the rock and fracture.

\subsection{Initial and boundary conditions}

The initial temperature and pressure of the reservoir are assumed to increase linearly from the top to the bottom, with a temperature gradient of $0.04 \mathrm{~K} / \mathrm{m}$ and a pressure gradient of $8500 \mathrm{~Pa} / \mathrm{m}$. The top temperature is $463.15 \mathrm{~K}$, and the top pressure is $42.875 \mathrm{MPa}$. Because the calculation domain is large enough, the boundary effect and water loss are ignored. The injection and production flow rates are both fixed, and the initial water temperature is $323.15 \mathrm{~K}$. The permeability of the overburden and underburden layers is very small compared with that of the SRV, so the zero-flow and thermal insulation conditions are exerted on the top and bottom boundaries. As for the lateral boundaries, the Dirichlet boundary is applied based on the initial pressure and temperature distribution. Detailed descriptions of the initial and boundary conditions are shown in Table 4.

\subsection{Solution method and mesh-convergence test}

\subsubsection{Solution method}

The equations are solved using the finite element solver COMSOL Multiphysics ${ }^{\circledR}$ 5.4. A two-dimensional model with a single-fracture is first used to verify the mathematical model

Table 4. Detailed descriptions of the initial and boundary conditions.

\begin{tabular}{ll}
\hline Description & Value \\
\hline Temperature gradient & $0.04 \mathrm{~K} / \mathrm{m}$ \\
Top boundary temperature & $463.15 \mathrm{~K}$ \\
Pressure gradient & $8500 \mathrm{~Pa} / \mathrm{m}$ \\
Top boundary pressure & $42.875 \mathrm{MPa}$ \\
Initial water temperature & $323.15 \mathrm{~K}$ \\
\hline
\end{tabular}

established in Section 3.1. As shown in Fig. 3, for this 2D model, the rock matrix and fracture are considered infinite in the horizontal and vertical ( $x$ and $y$ ) directions. The initial temperature of the rock is $T_{i}$, and the injection temperature and velocity of water are $T_{i n}$ and $u_{i n}$, respectively. The temperature distribution in the fracture can be solved according to the analytical solution proposed by Barends (2010):

$T_{f}=T_{i}+\left(T_{i n}-T_{i}\right) \operatorname{erfc}\left(\frac{\lambda_{s} x /\left(\rho_{w} c_{p, w} d_{f}\right)}{\sqrt{u_{\text {in }}\left(u_{\text {in }} t-x\right) \lambda_{s} / \rho_{s} c_{p, s}}}\right) U\left(t-\frac{x}{u_{\text {in }}}\right)$

where $T_{f}$ is the temperature along the fracture, erfc is the

\begin{tabular}{|c|c|}
\hline Description & Value \\
\hline Rock density $\rho_{s}$ & $2700 \mathrm{~kg} / \mathrm{m}^{3}$ \\
\hline Rock heat capacity $c_{p, s}$ & $1000 \mathrm{~J} /(\mathrm{kg} \cdot \mathrm{K})$ \\
\hline Rock heat conductivity $\lambda_{s}$ & $2.8 \mathrm{~W} /(\mathrm{m} \cdot \mathrm{K})$ \\
\hline Rock permeability $k_{s}$ & $1 \mathrm{mD}$ \\
\hline Rock porosity $\varphi_{s}$ & 0.15 \\
\hline Initial rock temperature $T_{i}$ & $353.15 \mathrm{~K}$ \\
\hline Water density $\rho_{w}$ & $1000 \mathrm{~kg} / \mathrm{m}^{3}$ \\
\hline Water heat capacity $c_{p, w}$ & $4200 \mathrm{~J} /(\mathrm{kg} \cdot \mathrm{K})$ \\
\hline Water viscosity $\mu_{f}$ & $0.001 \mathrm{~Pa} \cdot \mathrm{s}$ \\
\hline Injection velocity $u_{\text {in }}$ & $0.01 \mathrm{~m} / \mathrm{s}$ \\
\hline Injection temperature $T_{\text {in }}$ & $303.15 \mathrm{~K}$ \\
\hline Fracture aperture $d_{f}$ & $0.001 \mathrm{~m}$ \\
\hline Fracture density $\rho_{s}$ & $2000 \mathrm{~kg} / \mathrm{m}^{3}$ \\
\hline Fracture heat capacity $c_{p, f}$ & $850 \mathrm{~J} /(\mathrm{kg} \cdot \mathrm{K})$ \\
\hline Fracture heat conductivity $\lambda_{f}$ & $2.8 \mathrm{~W} /(\mathrm{m} \cdot \mathrm{K})$ \\
\hline Fracture permeability $k_{f}$ & $8.33 \times 10^{7} \mathrm{mD}$ \\
\hline Fracture porosity $\varphi_{f}$ & 1 \\
\hline Injection and production pressure difference $\Delta p$ & $1.2 \times 10^{4} \mathrm{~Pa}$ \\
\hline
\end{tabular}
complementary error function, and $U$ is the unit step function.

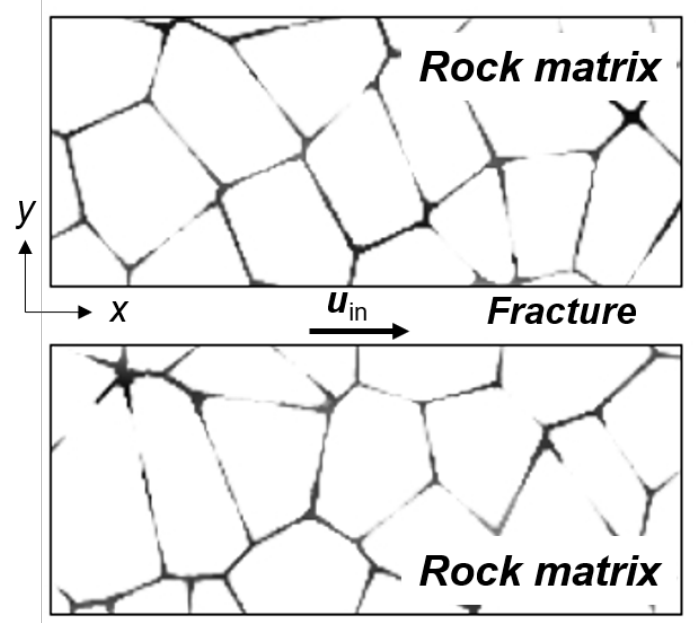

Fig. 3. Conceptual diagram of the $2 \mathrm{D}$ single-fracture model.

Table 5. The geological and boundary parameters used for validation. 


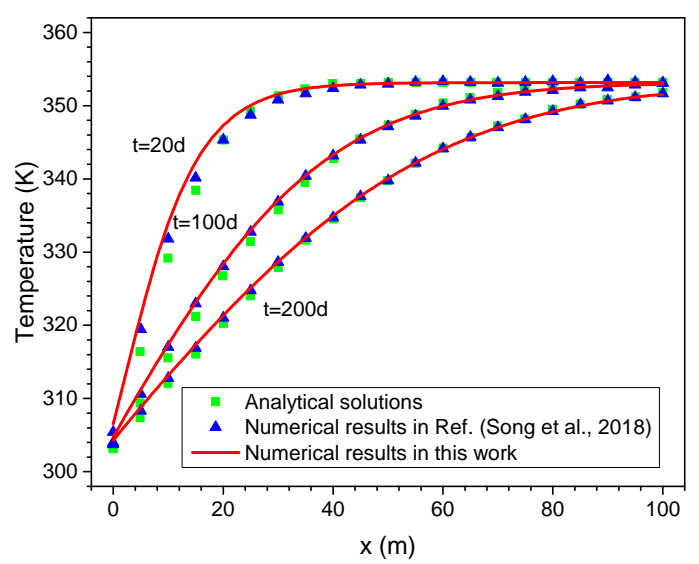

(a) Temperature distribution at different moments along the fracture.

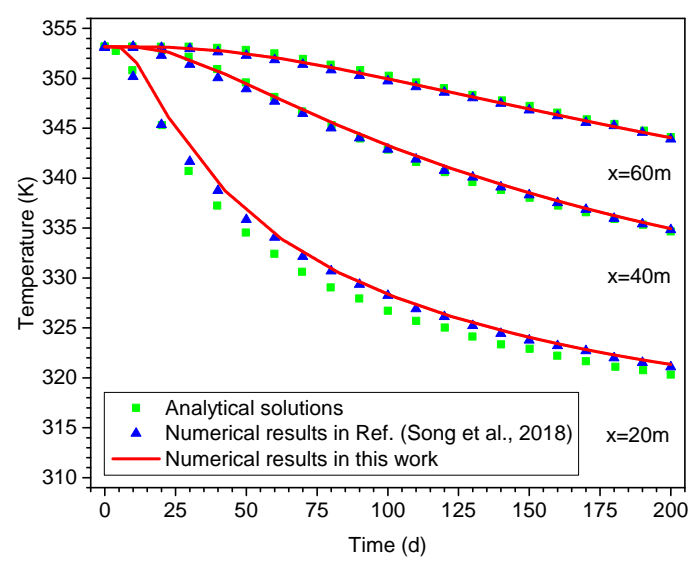

(b) Temperature evolution with time at three different locations in the fracture.

Fig. 4. Verification of the mathematical model.

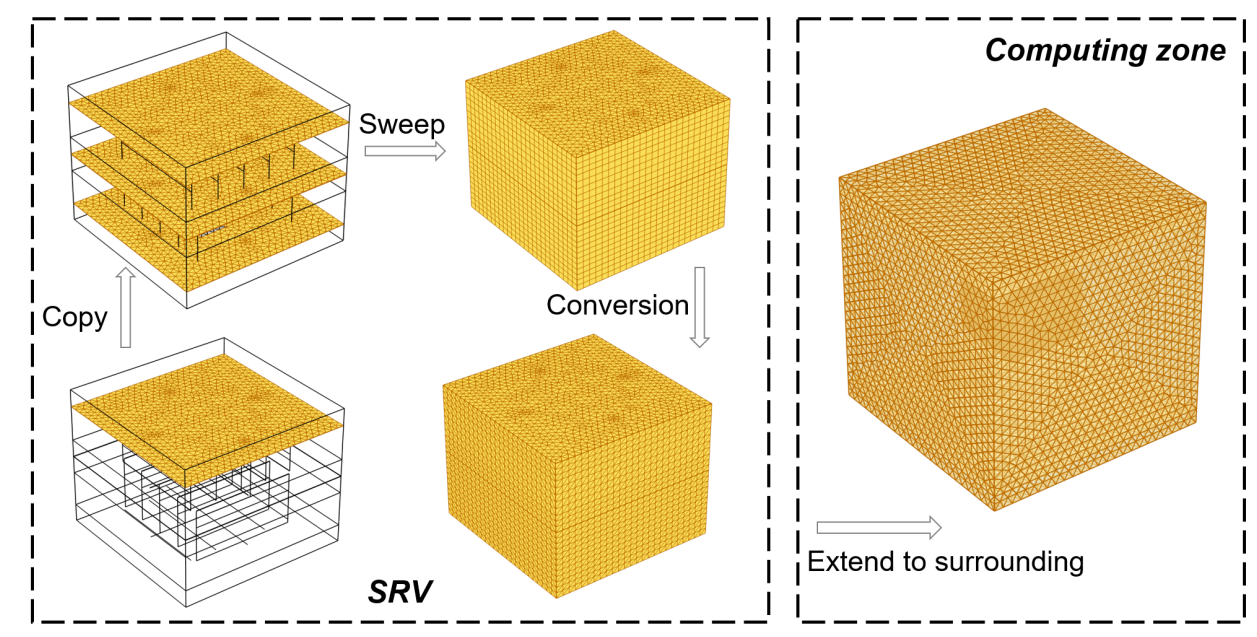

Fig. 5. Numerical meshing schemes.

In the computation domain of the $100 \mathrm{~m} \times 100 \mathrm{~m}$ rectangle, the numerical solution of the $2 \mathrm{D}$ model is calculated from the governing equations within the extraction time span of 200 days. The data and parameters used for validation are taken from the work of Song et al. (2018), and the detailed descriptions of the geological and boundary parameters are shown in Table 5. Fig. 4 shows the results of the comparison between the numerical solutions in this paper and the data in the reference (Song et al., 2018). The temperature distributions along the fracture at different moments (at the end of the $20^{\text {th }} \mathrm{d}, 100^{\text {th }} \mathrm{d}$, and $200^{\text {th }} \mathrm{d}$ ) are shown in Fig. 4(a), and the temperatures at different locations of the fracture $(20 \mathrm{~m}, 40$ $\mathrm{m}$, and $60 \mathrm{~m}$ ) are shown in Fig. 4(b). The numerical results of our model strongly agree with the numerical data of Song et al. (2018) as well as the analytical solutions.

\subsubsection{Mesh-convergence test}

The grid system exerts an important influence on the accuracy and efficiency of the numerical calculation. Increasing the number of grids can upgrade calculation accuracy but requires more calculating time. The grid system used in our work is

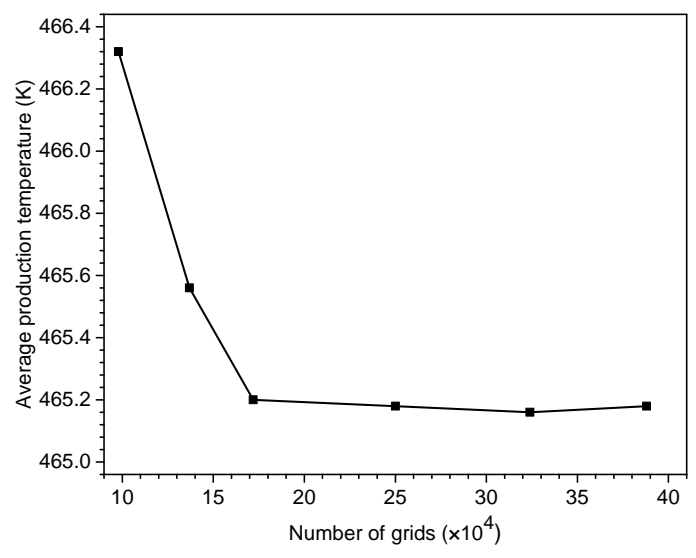

Fig. 6. Average production temperature with different grid numbers.

shown in Fig. 5. Because the SRV is the main area for heat and mass exchange, the grids in this zone are refined.

The average production temperatures at the end of the $30^{\text {th }}$ $\mathrm{yr}$ with different grid numbers are calculated for the meshconvergence validation. As shown in Fig. 6, when the number 
of grids exceeds 250,000 , the temperature changes only minimally. Therefore, to reduce computational load, the subsequent numerical simulation is carried out with the number of grids at about 250, 000. In the solver COMSOL Multiphysics ${ }^{\circledR} 5.4$, the backward difference method is used to discrete the transient term.

\section{Results and discussions}

Our previous work has shown that the thermal extraction performance and economic efficiency of $90^{\circ}$ interchangefracture EGS are better than those of conventional doublehorizontal well systems. The main objective of this work is to clarify the influence of stimulated reservoir volume permeability, fracture spacing, fracture aperture, water injection flow rate, and well spacing on the thermal extraction capacity of the $90^{\circ}$ interchange-fracture EGS. First, two horizontal planes $(Z=-4950 \mathrm{~m}$ and $Z=-5050 \mathrm{~m}$, which are at the upper and lower half of the stimulated reservoir, respectively) and a vertical plane $(Y=0 \mathrm{~m}$, which connects the injection well and the production well) were selected to analyze the distribution of the temperature field inside the stimulated reservoir volume. Then the thermal extraction capacity is compared. The evaluation indexes of heat mining performance are the average production temperature, output thermal power, and production pressure difference. In order to compare the effect of the change in production pressure difference and output thermal power on cost and income, a brief economic analysis is carried out in this paper, which focuses on the cost of electricity and income from thermal energy.

The average production temperature is defined as the average temperature of the production well, which can be described by:

$$
T_{\text {out }}=\frac{\int_{L_{2}} T(t) d l}{L_{2}}
$$

where $L_{2}$ is the production well length and $T(t)$ is the temperature of a certain position along the production well at time $t$.

The output thermal power directly reflects the heat generation capacity of the system, which can be described by:

$$
P=q_{m} c_{p, w}\left(T_{\text {out }}-T_{\text {in }}\right)
$$

where $q_{m}$ is the mass flow rate of the working fluid.
The average production pressure difference is the difference between the average pressure of the injection well and the production well, which can be described by:

$$
\Delta p=\frac{\int_{L_{1}} p_{\text {in }}(t) d l}{L_{1}}-\frac{\int_{L_{2}} p_{\text {out }}(t) d l}{L_{2}}
$$

where $L_{1}$ is the injection well length, and $p_{\text {in }}(t)$ and $p_{\text {out }}(t)$ are the pressure of the injection well and the production well at time $t$, respectively.

The power cost of the system is mainly the cost of the electric energy consumed by the pump. According to the research of Pollack et al. (2019), the electric cost can be described as follows:

$$
E_{\text {sys }}=E_{\text {pump }}=t p_{e} q_{m} \Delta p
$$

where $p_{e}$ is the unit price of electric energy, $0.138 \$ /(\mathrm{KW} \cdot \mathrm{h})$ in this paper.

The heat energy produced by the system can be applied to power generation and heating. The heat energy income can be described by:

$$
\begin{gathered}
Q_{u}=\eta \int_{0}^{t} q_{\mathrm{m}} c_{p, f}\left(T_{\text {out }}-T_{\text {in }}\right) d t \\
I_{u}=p_{u} Q_{u} t
\end{gathered}
$$

where $Q_{u}$ denotes the heat energy generated by the system, $\eta$ is the heat-exchange efficiency and takes $80 \%$, and $p_{u}$ is the unit price of heat energy, $0.083 \$ /(\mathrm{KW} \cdot \mathrm{h})$ in this paper.

\subsection{Influence of stimulated reservoir volume permeability}

In this section, the influence of stimulated reservoir volume permeability on the thermal extraction performance of the $90^{\circ}$ interchange-fracture EGS is analyzed. Fig. 7 shows the temperature distributions in the SRV at different permeabilities at the end of the $30^{\text {th }}$ year. As shown in the figure, the range of the cooling zone on the two horizontal sections increases with the increase in permeability. This means that a higher stimulated reservoir volume permeability helps to increase the area of heat transfer between the fluid and the rock, allowing more heat to be mined from the SRV. In the vertical section, the temperature of the rock around the production well increases with the increase of permeability. This suggests that a higher

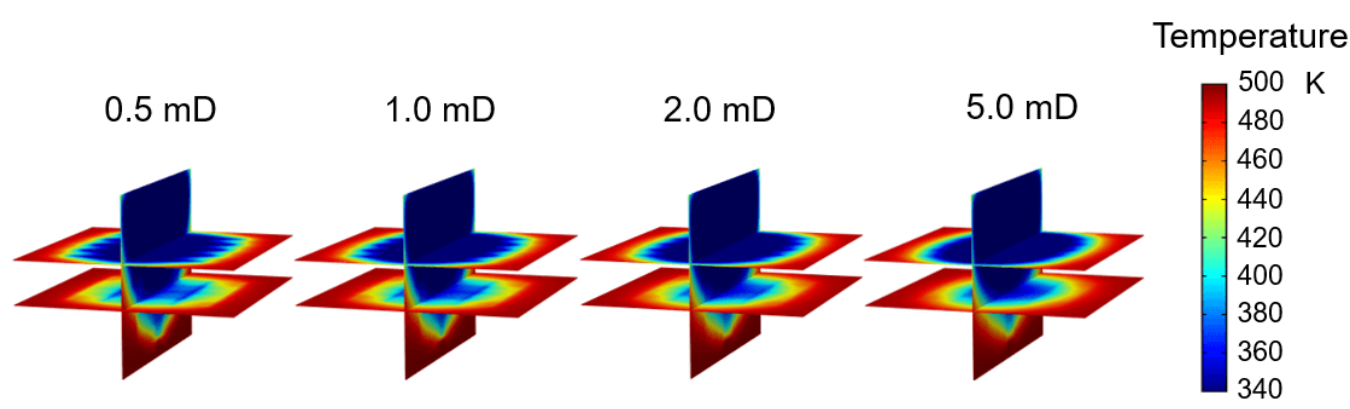

Fig. 7. Temperature distributions at different stimulated reservoir volume permeabilities at the end of the $30^{\text {th }}$ year. 


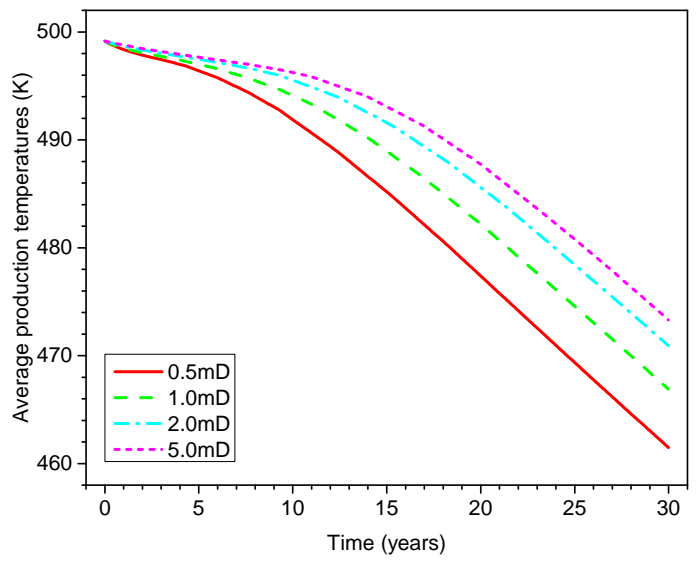

(a)

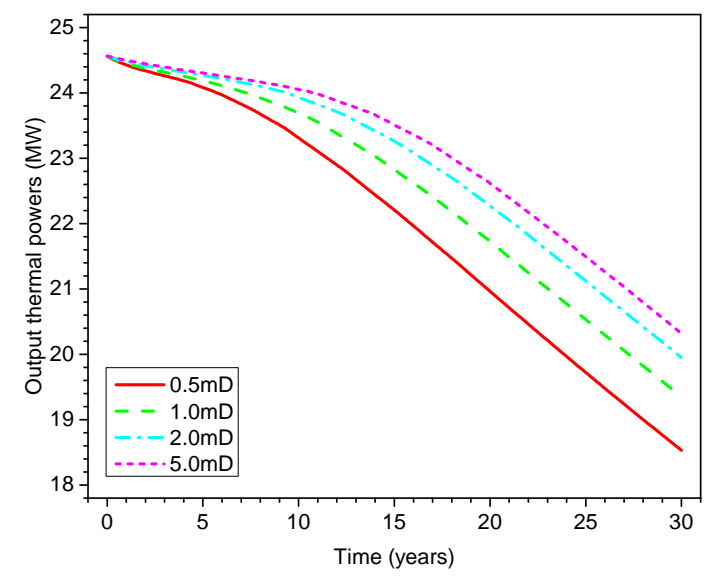

(b)

Fig. 8. Average production temperatures and output thermal powers at different stimulated reservoir volume permeabilities.

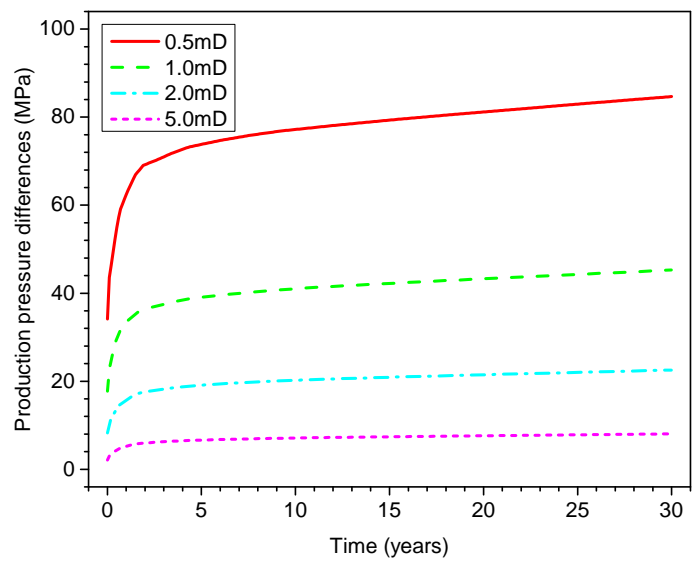

Fig. 9. Production pressure differences at different stimulated reservoir volume permeabilities.

stimulated reservoir volume permeability has the potential for obtaining a higher production temperature.

Fig. 8 shows the average production temperatures and output thermal powers at different stimulated reservoir volume permeabilities. Fig. 9 shows production pressure differences. As shown in Fig. 8, the average production temperature increases with the increase in permeability; the trend of output thermal power is similar to that of temperature. This is consistent with the analysis in Fig. 7. Fig. 9 shows that the higher the stimulated reservoir volume permeability is, the smaller will be the pressure difference required for production. This is because a higher permeability correlates to a lower flow resistance, and lower resistance helps the fluid flow through a larger area, which is beneficial for increasing heat transfer efficiency and the heat extraction rate. It is worth noting that when the permeability is $0.5 \mathrm{mD}$, the production temperature increases by $5.4 \mathrm{~K}$ for each doubling of permeability, while when the permeability is greater than $2 \mathrm{mD}$, the production temperature will increase by less than $2.4 \mathrm{~K}$ for each doubling of permeability. This indicates that with the increase of stimulated reservoir volume permeability, the impact on heat mining performance is gradually weakened. Moreover, compared with the production temperature, the pressure difference is more sensitive to permeability change.

Fig. 10 shows the electricity costs and heat incomes of

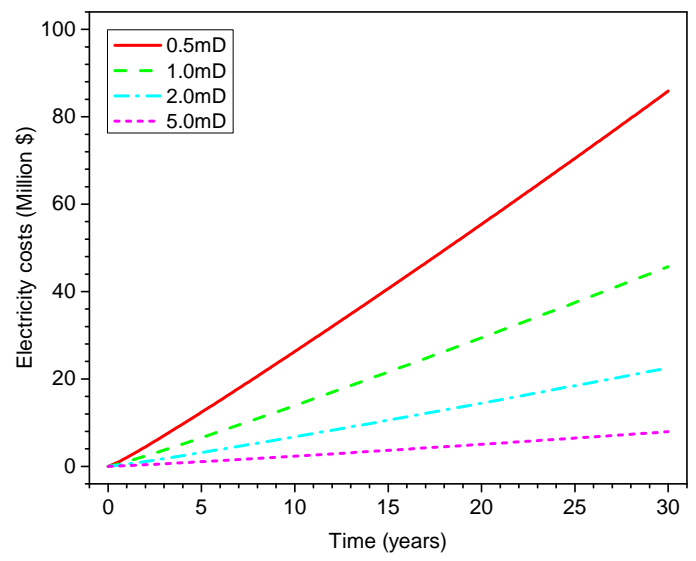

(a)

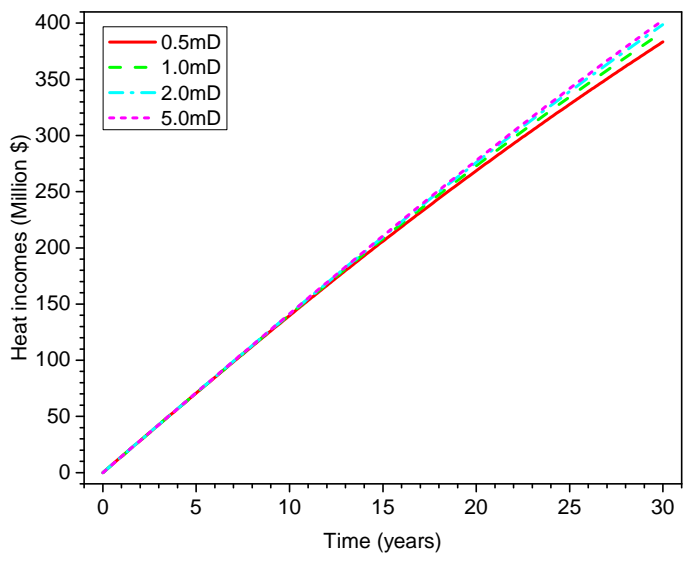

(b)

Fig. 10. Electricity costs and heat incomes at different stimulated reservoir volume permeabilities. 


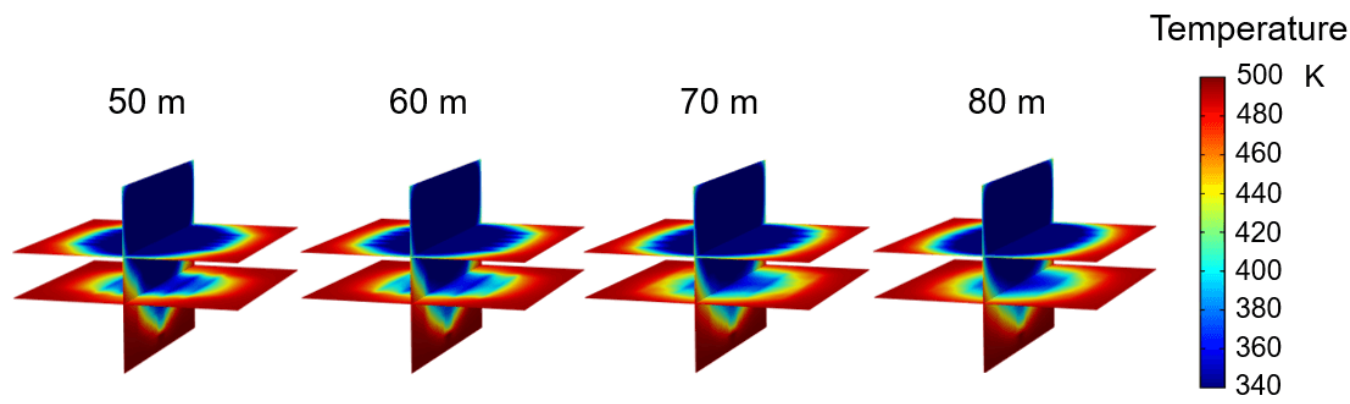

Fig. 11. Temperature distributions at different fracture spacings at the end of the $30^{\text {th }}$ year.

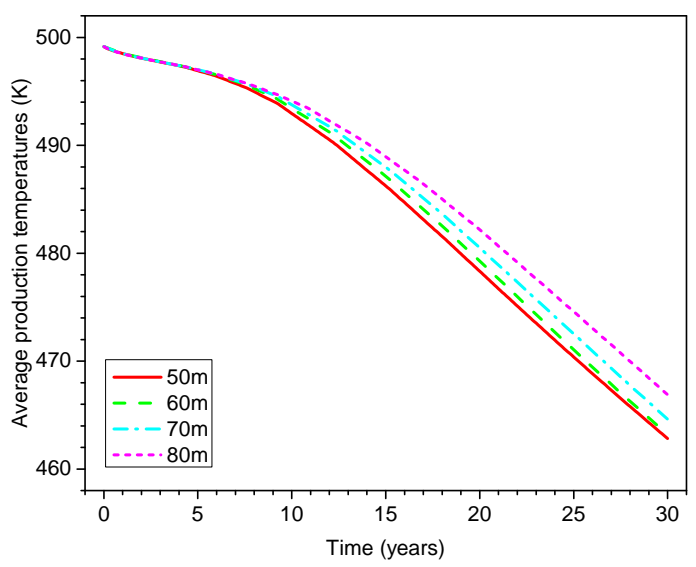

(a)

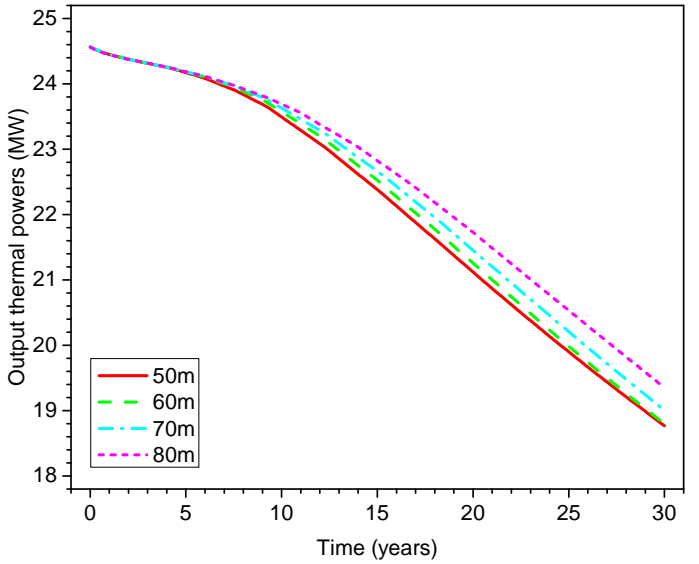

(b)

Fig. 12. Average production temperatures and output thermal powers at different fracture spacings.

$90^{\circ}$ interchange-fracture EGS at different stimulated reservoir volume permeability levels. As shown in Fig. 10(a), there is a significant difference in electricity costs between different permeability levels, and a larger permeability is conducive to significant cost savings. Fig. 10(b) shows that heat income increases with the increase of permeability. Therefore, measures should be taken to increase stimulated reservoir volume permeability, reduce electricity costs, and increase thermal energy return.

\subsection{Influence of fracture spacing}

In this section, the influence of fracture spacing on the thermal extraction performance of the $90^{\circ}$ interchange-fracture EGS is analyzed. Fig. 11 shows the temperature distributions in the SRV at different fracture spacings at the end of the $30^{\text {th }}$ year. As can be seen, fractures are the main channels for fluid flow, and the heat transfer area (cooling area) is also mainly concentrated around the fractures. In the figure, the heat transfer zone increases with the increase of fracture spacing. It is worth noting that, when the fracture spacing is $80 \mathrm{~m}$, we see not only the largest heat transfer area, but also a distinct fracture profile in the section $Z=-4950 \mathrm{~m}$. However, when the fracture spacing is only $50 \mathrm{~m}$, not only is the heat transfer region reduced, but also the fracture profile is no longer obvious. This means that a small fracture spacing will aggravate the thermal interference between fractures, which is not conducive to heat mining.

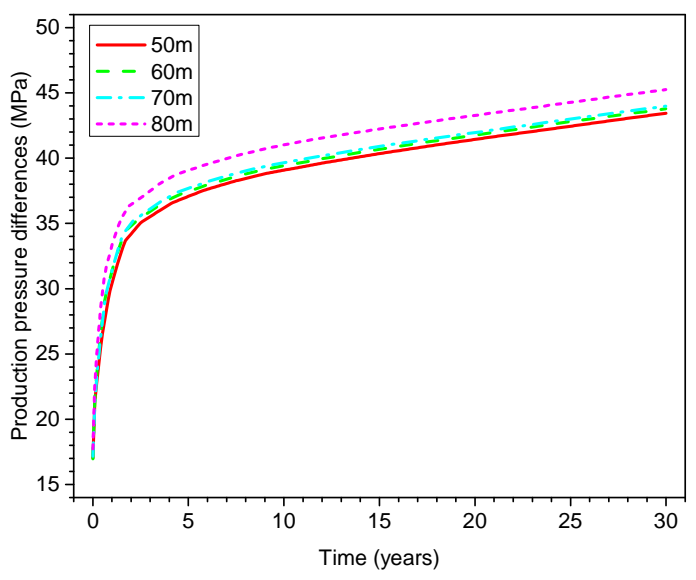

Fig. 13. Production pressure differences at different fracture spacings.

Fig. 12 shows the average production temperatures and output thermal powers at different fracture intervals. With an increase in fracture spacing, the average production temperature and output thermal power of the system are improved. This is because fractures are the main channel for the working medium flow, and larger fracture spacing helps the fluid within the fractures radiate to a wider area and increases the heat transfer area. However, in Fig. 13, by comparing the production pressure difference corresponding to different fracture spacing, we find that with the increase of spacing, the 


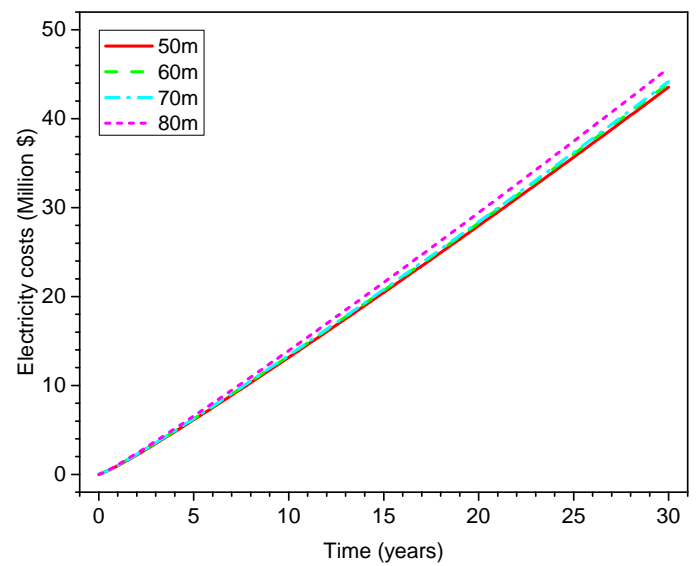

(a)

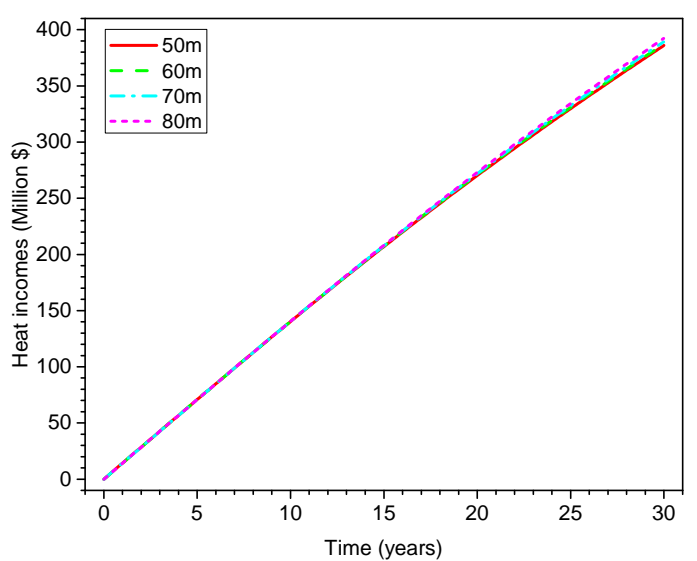

(b)

Fig. 14. Electricity costs and heat incomes at different fracture spacings.

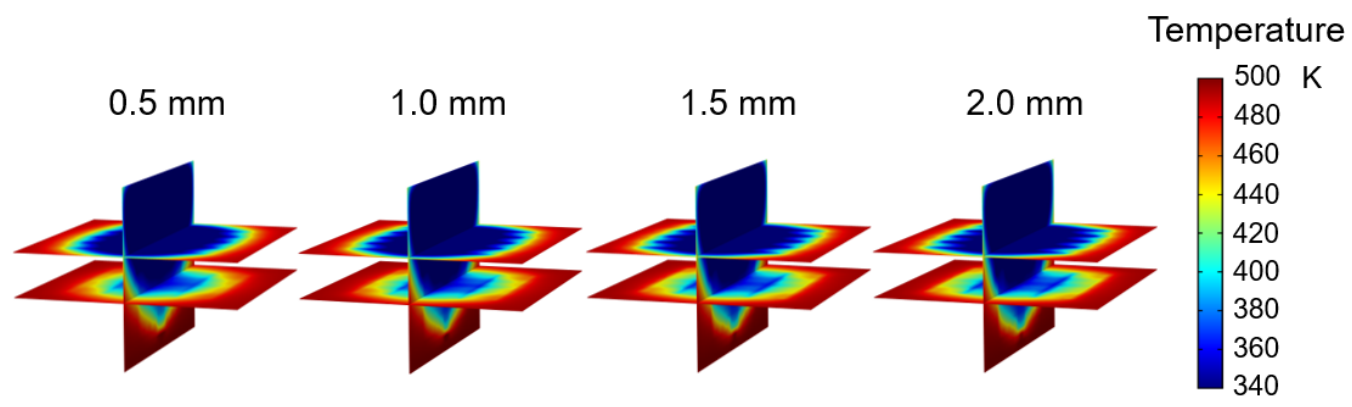

Fig. 15. Temperature distributions at different fracture apertures at the end of the $30^{\text {th }}$ year.

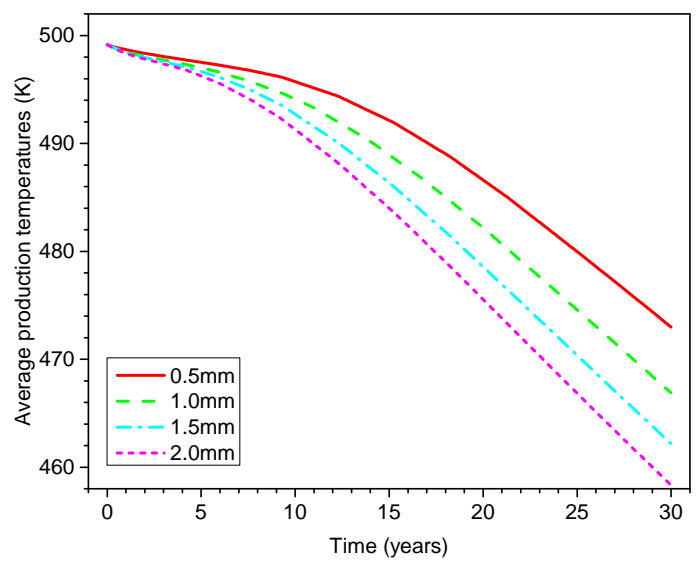

(a)

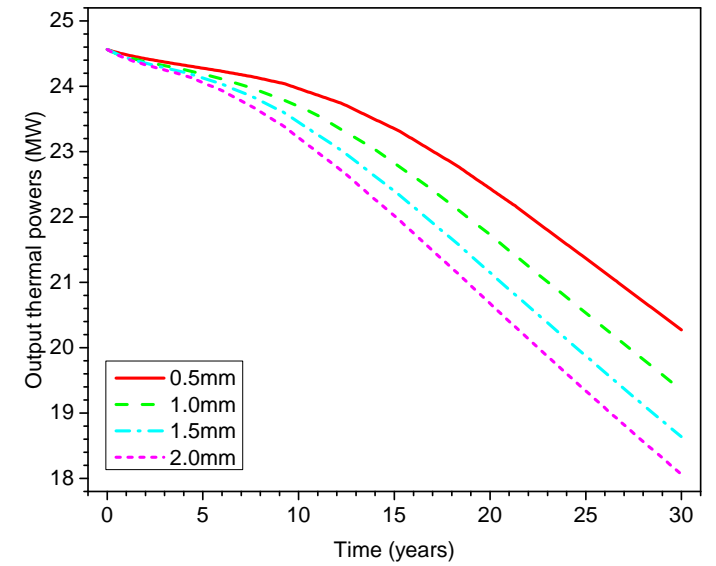

(b)

Fig. 16. Average production temperatures and output thermal powers at different fracture apertures.

required production pressure difference also increases. This is because the resistance loss of fluid flow will also increase with the increase of the heat transfer area. However, when the fracture spacing is less than $60 \mathrm{~m}$, the effect of changing the fracture spacing on production temperature and pressure difference is not significant.

The electricity costs and thermal energy incomes at different fracture spacings are shown in Fig. 14. Both the income and the cost increase with the increase of spacing. However, when the fracture interval is $80 \mathrm{~m}$, the total electricity cost over 30 years is $\$ 45.71$ million and the total heat income is $\$ 392.36$ million, which increases only $\$ 1.49$ million and $\$ 2.90$ million, respectively, compared with a spacing of $70 \mathrm{~m}$. This suggests that the $90^{\circ}$ interchange-fracture EGS is less sensitive to changes in fracture spacing than SRV permeability.

\subsection{Influence of fracture aperture}

In this section, the influence of fracture aperture on the thermal extraction performance of $90^{\circ}$ interchange-fracture EGS is analyzed. Fig. 15 shows the temperature distributions 


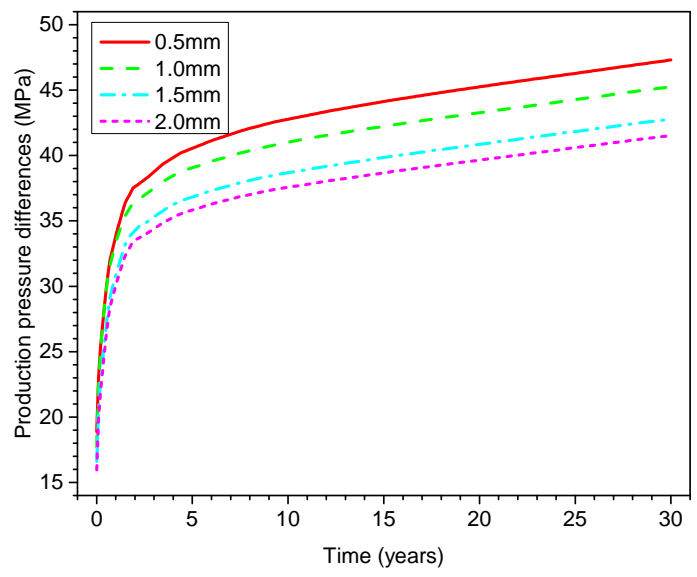

Fig. 17. Production pressure differences at different fracture apertures.

in the SRV at different fracture apertures at the end of the $30^{\text {th }}$ year. As can be seen, the range of the cooling zone on the two horizontal sections decreases with the increase of the fracture aperture, while the temperature of the rock around the production well is the opposite. This means that increasing the fracture aperture results in more fluid arriving at the production well through the fracture, rather than through the hot dry rock porous media. That is, increasing fracture aperture will lead to a heat short circuit.

The average production temperatures and output thermal powers at different fracture apertures are shown in Fig. 16. Both the average production temperature and the output thermal power decrease with an increase of fracture aperture, and the smaller aperture can obtain a larger heat output. This is consistent with the analysis in Fig. 15. A larger aperture will lead to thermal short circuits, which is not conducive to the full extraction of reservoir heat. However, as shown in Fig. 17, the smaller the fracture apertures, the greater the flow resistance loss, resulting in a larger production pressure difference. Therefore, it is necessary to combine the magnitude of temperature difference and economic analysis to see whether a small fracture aperture is desirable or not.

Fig. 18 shows the economic analysis under different fracture apertures. Both electricity cost and thermal income increase with a decrease of the fracture aperture. Each 0.5 $\mathrm{mm}$ reduction in fracture aperture increases electricity costs by approximately $\$ 2$ million and economic incomes by approximately $\$ 7$ million. In contrast, the smaller fracture aperture has more economic advantages.

\subsection{Influence of injection flow rate}

In this section, the influence of the injection flow rate on the thermal extraction performance of the $90^{\circ}$ interchangefracture EGS is analyzed. Fig. 19 shows the temperature distributions in the SRV at different injection flow rates at the end of the $30^{\text {th }}$ year. As shown in the figure, the range of the cooling zone increases with the increase of the injection

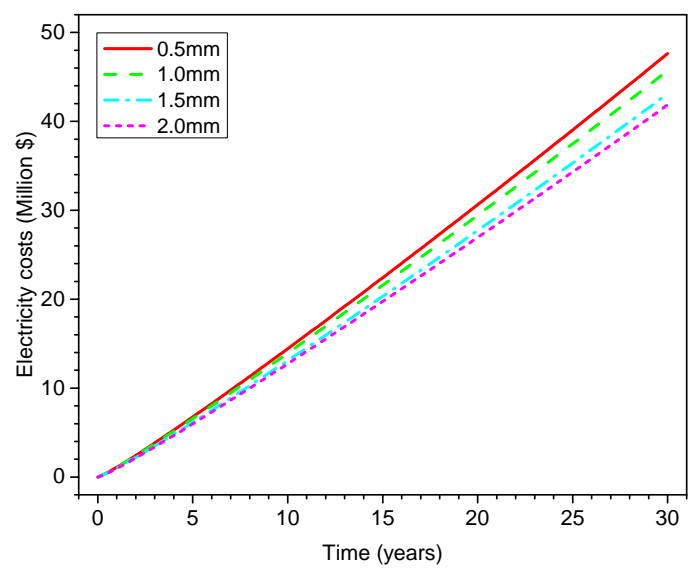

(a)

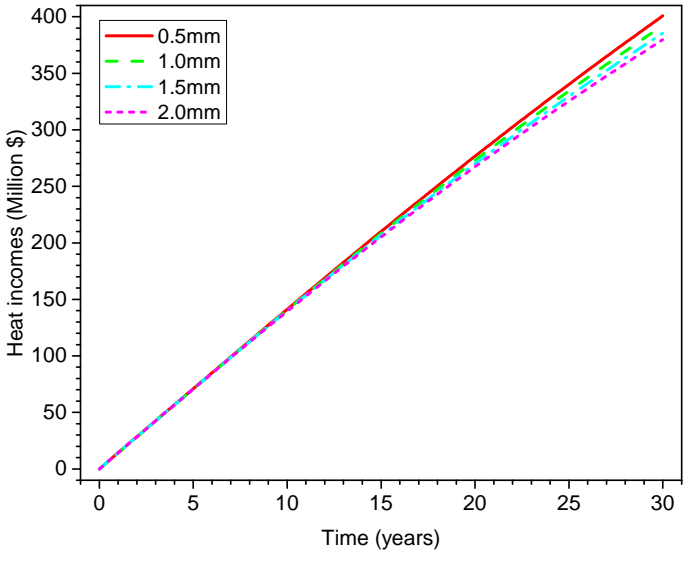

(b)

Fig. 18. Electricity costs and heat incomes at different fracture apertures.

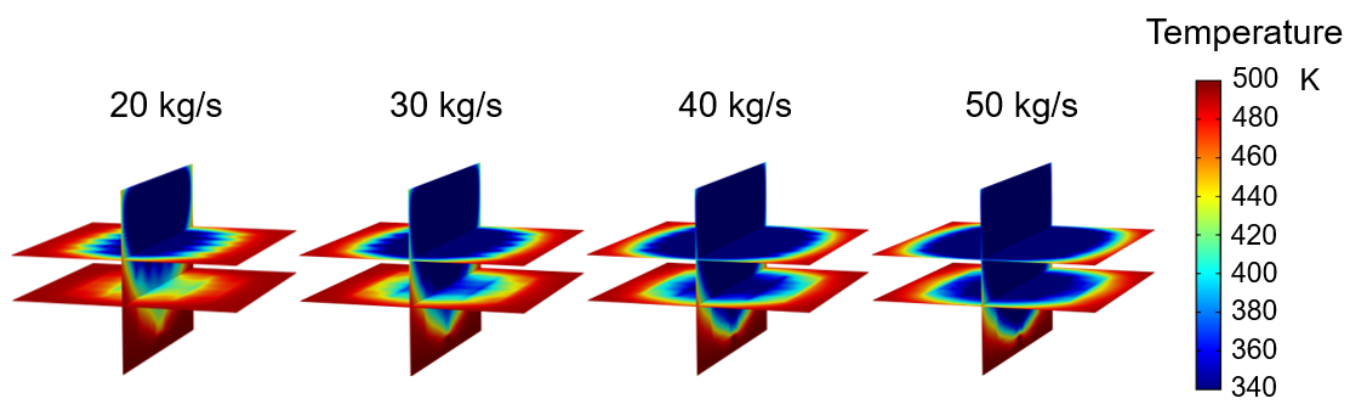

Fig. 19. Temperature distributions at different injection flow rates at the end of the $30^{\text {th }}$ year. 


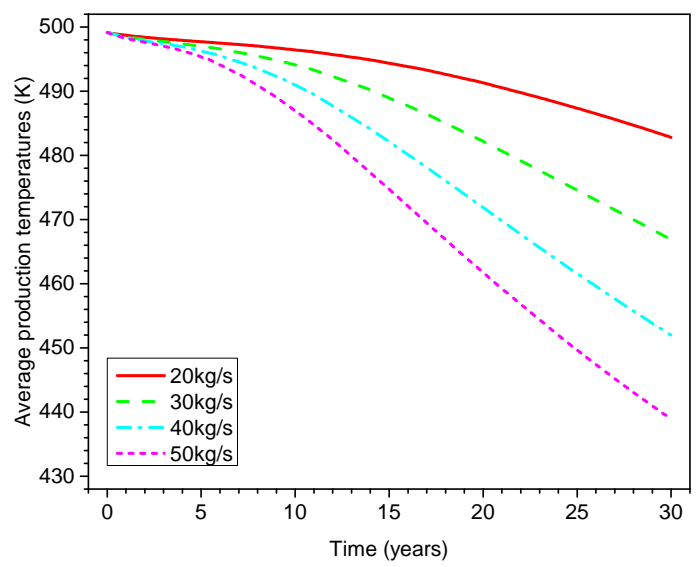

(a)

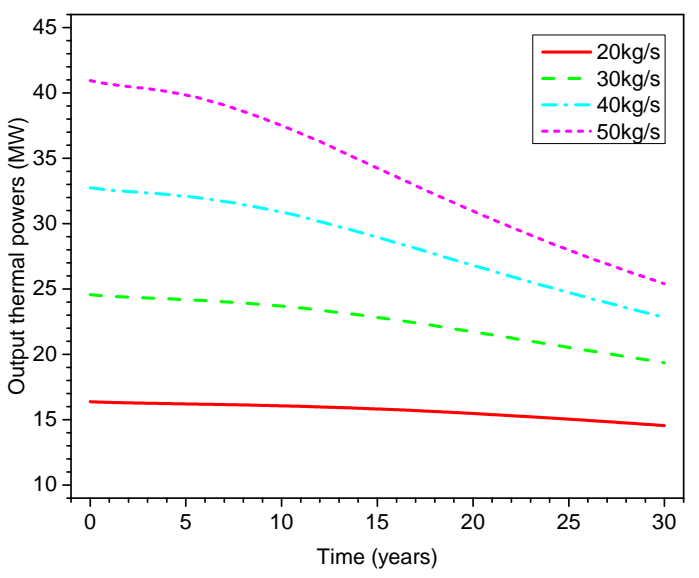

(b)

Fig. 20. Average production temperatures and output thermal powers at different injection flow rates.

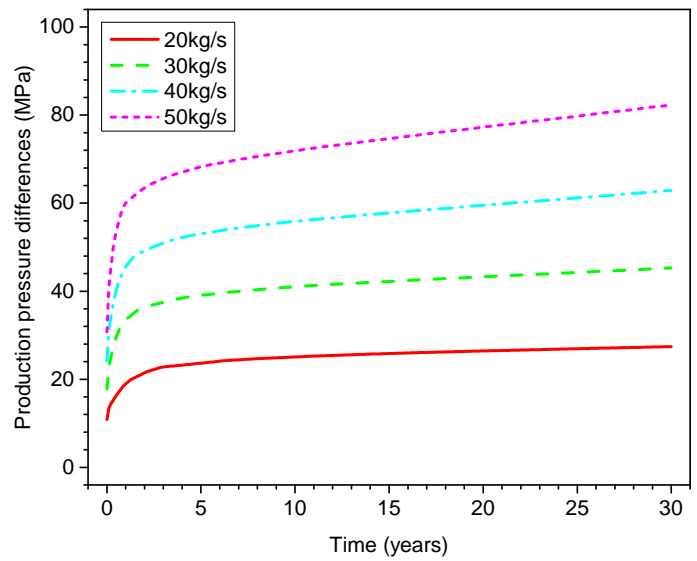

Fig. 21. Production pressure differences at different injection flow rates.

flow rate, and at the same time the temperature around the production well decreases. On one hand, increasing the injection amount of working medium can extract more heat from the SRV. On the other hand, as the heat stored in the SRV is extracted in large quantities, the area of the cold zone expands, and when the cold zone reaches the production well earlier, thermal breakthrough is more likely to take place.

The average production temperatures and output thermal powers at different injection flow rates are shown in Fig. 20. It can be seen from Fig. 20(a) that as the injection flow rate increases, the average production temperature drops faster. At the end of $30^{\text {th }}$ year, the production temperature with a flow rate of $20 \mathrm{~kg} / \mathrm{s}$ is $482.82 \mathrm{~K}$, while the output temperature with $50 \mathrm{~kg} / \mathrm{s}$ is only $438.9 \mathrm{~K}, 43.93 \mathrm{~K}$ lower than the former. Fig. 20(b) shows that the greater the injection flow rate, the greater the output thermal power of the system. However, a small injection flow rate can ensure a stable output thermal power of the system in the long term, and the larger the injection flow rate, the faster the output thermal power decreases with the extension of heat extraction time. As shown in Fig. 21, with an increase of the injection flow rate, the pressure loss increases rapidly. A smaller flow rate is more conducive to obtaining a stable production pressure difference, while a larger flow rate increases production pressure difference year by year. This is because the larger flow rate also accelerates the cooling of the reservoir in addition to extracting more heat from the reservoir, reducing the heat transfer temperature difference and increasing flow resistance. This eventually leads to an earlier thermal breakthrough of the system, which is not conducive to the long-term stable operation of the system.

Fig. 22 shows electricity costs and heat incomes at different injection flow rates. We found that, as the injection flow rate increases, both electricity cost and heat income increase. The difference is that the cost increases by $\$ 27.19$ million, $\$ 37.82$ million, and $\$ 51.76$ million for each increase of 10 $\mathrm{kg} / \mathrm{s}$, showing an increasing trend, while income increases by $\$ 118.78$ million, $\$ 105.56$ million, and $\$ 94.27$ million, respectively, showing a decreasing trend. This is because the higher the flow rate is, the faster the reservoir cools, resulting in a smaller heat transfer temperature difference and greater fluid viscosity and flow resistance. However, overall it is still economical to increase the flow rate. Moreover, heat income is more sensitive to a change of the injection flow rate than to the other three influencing factors.

\subsection{Influence of well spacing}

In this section, the influence of well spacing on the thermal extraction performance of the $90^{\circ}$ interchange-fracture EGS is analyzed. Fig. 23 shows the temperature distributions in the SRV at different well spacings at the end of $30^{\text {th }}$ year. As can be seen, the temperature of the rock around the production well increases with the distance between the injection well and the production well. The well-fracture system is the primary path for fluid flow, and the longer the distance between two wells, the longer the path. This in turn helps delay the arrival of the cold zone to the production well, and delays the thermal breakthrough. Moreover, when the size of the SRV is constant, a larger well spacing results in the production well being closer to the edge of the SRV, helping to gain more heat compensation from the surrounding HDR layer.

Fig. 24 shows the average production temperatures and 


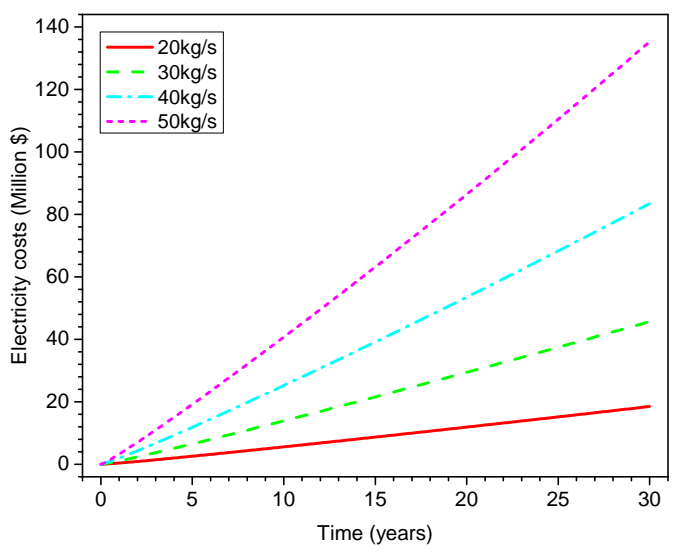

(a)

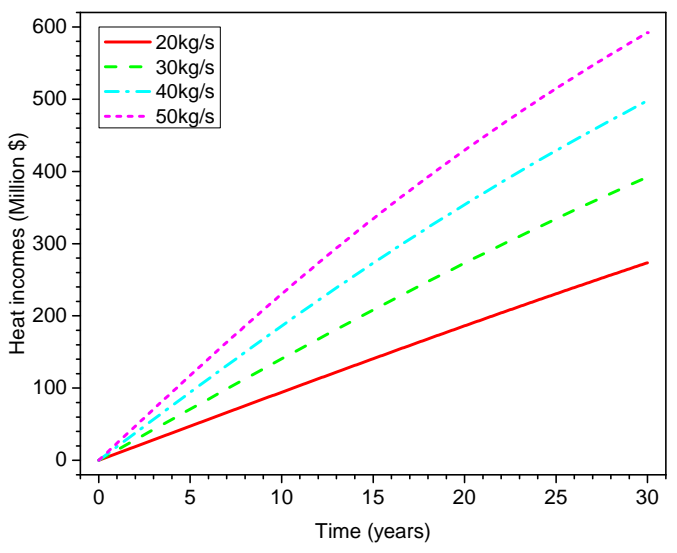

(b)

Fig. 22. Electricity costs and heat incomes at different injection flow rates.

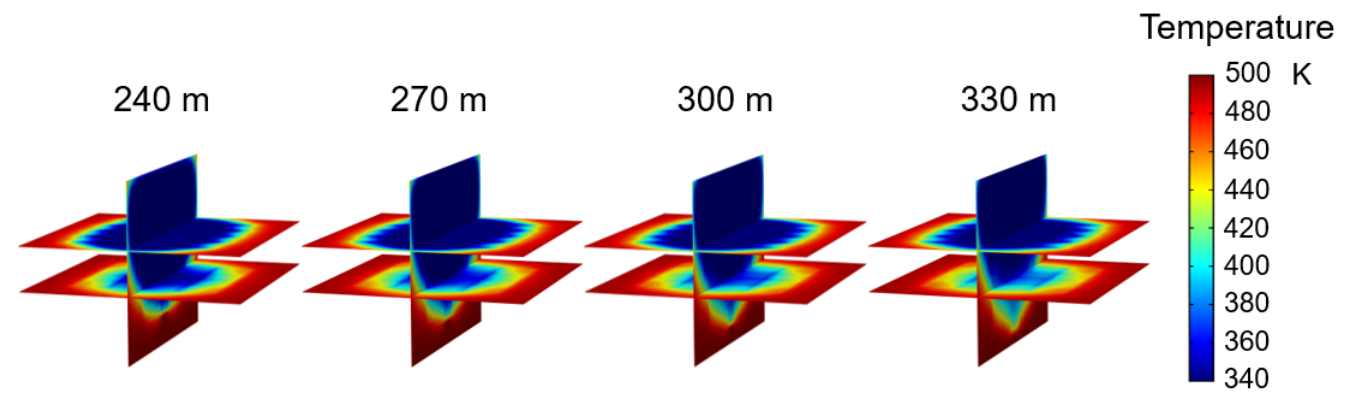

Fig. 23. Temperature distributions at different well spacings at the end of $30^{\text {th }}$ year.

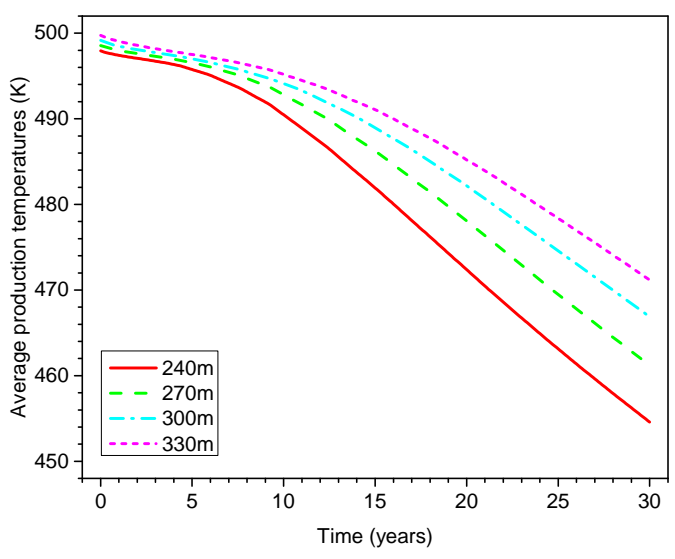

(a)

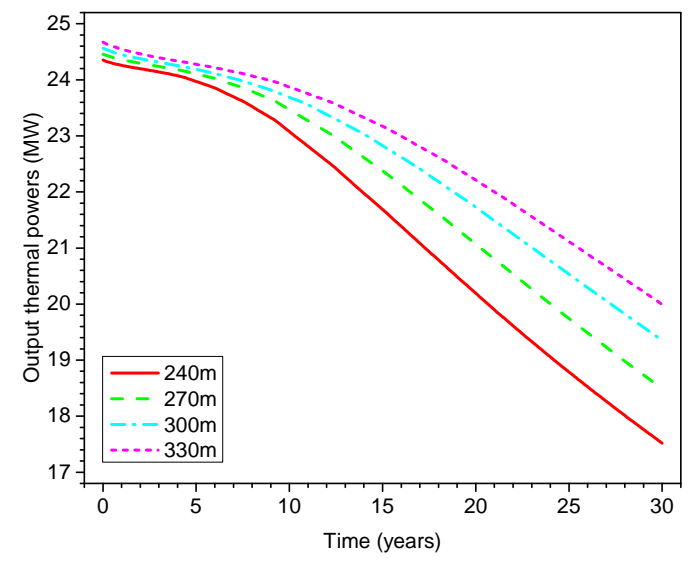

(b)

Fig. 24. Average production temperatures and output thermal powers at different well spacings.

output thermal powers at different well spacings. Similarly to the analysis in Fig. 23, the average production temperature and output thermal power of the system increase with the increase in well spacing. Increasing well spacing helps to extend the flow path of the working fluid and increases the heat transfer area. However, the flow resistance loss increases with the increase in well spacing, as shown in Fig. 25. Therefore, the electricity cost is compared with thermal energy income to evaluate the gain and loss of both.

The electricity costs and thermal energy incomes at different well spacings are shown in Fig. 26. Both the income and the cost increase with the increase in well spacing. However, for each $30 \mathrm{~m}$ increase/decrease in well spacing, the cost increase/decrease due to pump power consumption is no more than $\$ 2$ million, while thermal income increased/decreased by at least $\$ 6$ million. In their review of previous work, Pollack and Mukerji (2019) noted that the drilling costs increase by approximately $\$ 16,230$ to $\$ 50,430$ per $30 \mathrm{~m}$ of vertical well depth increase, which is a small change compared to thermal income. Therefore, a larger well spacing helps increase thermal income. 


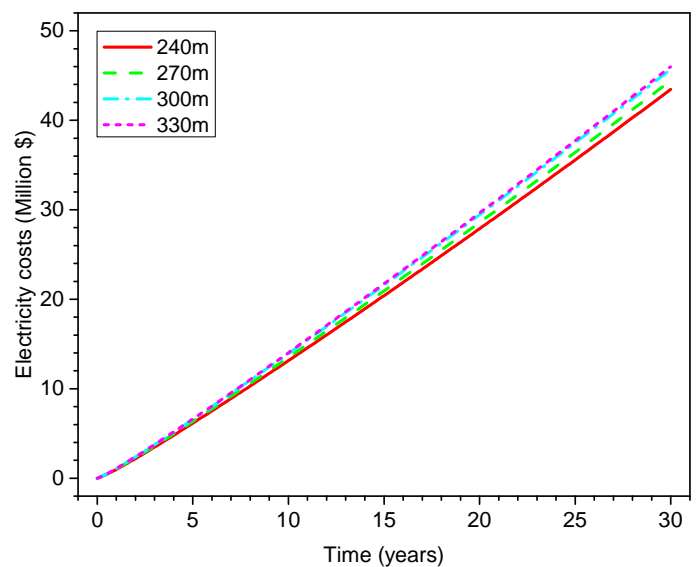

(a)

Fig. 26. Electricity costs and heat incomes at different well spacings.

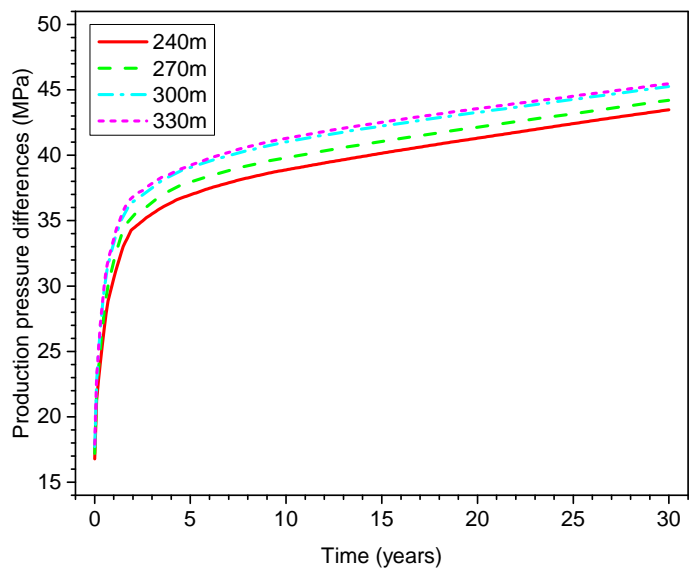

Fig. 25. Production pressure differences at different well spacings.

\section{Conclusions}

In this paper, a three-dimensional, unsteady thermal and hydraulic model for a $90^{\circ}$ interchange-fracture EGS is established, and the effects of pivotal parameters on the heat mining performance of this proposed system are studied. The main findings are as follows:

1) The $90^{\circ}$ interchange-fracture EGS is most sensitive to stimulated reservoir volume permeability and injection flow rate, while fracture spacing, fracture aperture, and well spacing show less influence on the system.

2) Improving stimulated reservoir volume permeability leads to higher output thermal power and a smaller production pressure difference for the $90^{\circ}$ interchange-fracture EGS, which saves power costs and gives higher economic benefits.

3) Increasing fracture spacing, decreasing fracture aperture, and increasing well spacing are beneficial to improving the output thermal power of the $90^{\circ}$ interchange-fracture EGS, but require a larger production pressure difference, leading to an increase of power costs.

4) Increasing the injection flow rate is conducive to obtaining higher-output thermal power and increasing economic

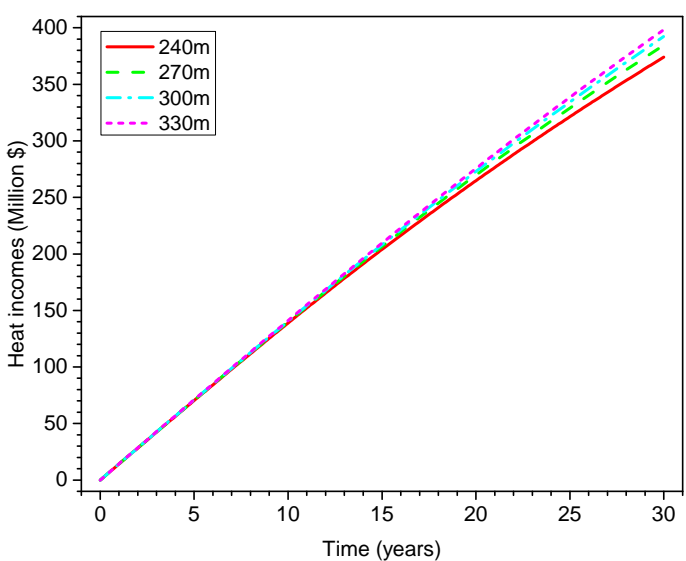

(b)

income, but leads to a greater production pressure difference, which is not conducive to the long-term stable operation of the system.

This study has definite guiding significance for the development and utilization of interchange-fracture EGS. It is worth mentioning that the influence of formation stress and anisotropy of rock properties on the system are not considered in this work. In future studies, formation stress should be taken into account, and a more complete economic analysis will be carried out.

\section{Acknowledgement}

The authors gratefully acknowledge the financial support of the National Natural Science Foundation of China (No. 51606117), and the Natural Science Foundation of Shanghai (No. 20ZR1423300).

\section{Conflict of interest}

The authors declare no competing interest.

Open Access This article is distributed under the terms and conditions of the Creative Commons Attribution (CC BY-NC-ND) license, which permits unrestricted use, distribution, and reproduction in any medium, provided the original work is properly cited.

\section{References}

Abdel-Salam, M. R. H., Zaidi, A. Field study of cooling performance of two ground-source heat pumps in Canadian single-family houses. Applied Thermal Engineering, 2021, 184: 116294.

Aliyu, M. D., Archer, R. A. Numerical simulation of multifracture HDR geothermal reservoirs. Renewable Energy, 2021, 164: 541-555.

Anyim, K., Gan, Q. Fault zone exploitation in geothermal reservoirs: Production optimization, permeability evolution and induced seismicity. Advances in Geo-Energy Research, 2020, 4(1): 1-12.

Bai, Q., Liu, Z., Zhang, C., et al. Geometry nature of hydraulic fracture propagation from oriented perforations and implications for directional hydraulic fracturing. 
Computers and Geotechnics, 2020, 125: 103682.

Barends, F. Complete solution for transient heat transport in porous media, following Lauwerier's concept. Paper SPE 134670 Presented at SPE Annual Technical Conference and Exhibition, Florence, Italy, 19-22 September, 2010.

Bongole, K., Sun, Z., Yao, J. Potential for geothermal heat mining by analysis of the numerical simulation parameters in proposing enhanced geothermal system at Bongor Basin, Chad. Simulation Modelling Practice and Theory, 2021, 107: 102218.

Bujakowski, W., Barbacki, A., Miecznik, M., et al. Modelling geothermal and operating parameters of EGS installations in the lower triassic sedimentary formations of the central Poland area. Renewable Energy, 2015, 80: 441-453.

Chen, S., Ding, B., Gong, L., et al. Comparison of multi-field coupling numerical simulation in hot dry rock thermal exploitation of enhanced geothermal systems. Advances in Geo-Energy Research, 2019, 3(4): 396-409.

Ding, J., Wang, S. 2D modeling of well array operating enhanced geothermal system. Energy, 2018, 162: 918932.

Gong, F., Guo, T., Sun, W., et al. Evaluation of geothermal energy extraction in Enhanced Geothermal System (EGS) with multiple fracturing horizontal wells (MFHW). Renewable Energy, 2020, 151: 1339-1351.

Habibzadeh-Bigdarvish, O., Yu, X., Li, T., et al. A novel full-scale external geothermal heating system for bridge deck de-icing. Applied Thermal Engineering, 2021, 185: 116365.

Holzbecher, E. O. Modeling Density-Driven Flow In Porous Media. Berlin, German, Springer, 1998.

Ijeje, J. J., Gan, Q., Cai, J. Influence of permeability anisotropy on heat transfer and permeability evolution in geothermal reservoir. Advances in Geo-Energy Research, 2019, 3(1): 43-51.

Lei, Z., Zhang, Y., Yu, Z., et al. Exploratory research into the enhanced geothermal system power generation project: The Qiabuqia geothermal field, Northwest China. Renewable Energy, 2019, 139: 52-70.

Lei, Z., Zhang, Y., Zhang, S., et al. Electricity generation from a three-horizontal-well enhanced geothermal system in the Qiabuqia geothermal field, China: Slickwater fracturing treatments for different reservoir scenarios. Renewable Energy, 2020, 145: 65-83.

Li, K., Bian, H., Liu, C., et al. Comparison of geothermal with solar and wind power generation systems. Renewable and Sustainable Energy Reviews, 2015, 42: 1464-1474.

Liao, Y., Sun, X., Sun, B., et al. Geothermal exploitation and electricity generation from multibranch U-shaped wellenhanced geothermal system. Renewable Energy, 2021, 163: 2178-2189.
Ma, Y., Li, S., Zhang, L., et al. Numerical simulation study on the heat extraction performance of multi-well injection enhanced geothermal system. Renewable Energy, 2020, 151: 782-795.

Ma, Y., Li, S., Zhang, L., et al. Study on the effect of well layout schemes and fracture parameters on the heat extraction performance of enhanced geothermal system in fractured reservoir. Energy, 2020, 202: 117811.

Pollack, A., Mukerji, T. Accounting for subsurface uncertainty in enhanced geothermal systems to make more robust techno-economic decisions. Applied Energy, 2019, 254: 113666.

Shi, Y., Song, X., Shen, Z., et al. Numerical investigation on heat extraction performance of a $\mathrm{CO}_{2}$ enhanced geothermal system with multilateral wells. Energy, 2018, 163: 38-51.

Song, X., Yu, S., Li, G., et al. Numerical simulation of heat extraction performance in enhanced geothermal system with multilateral wells. Applied Energy, 2018, 218: 325337.

Sun, F., Yao, Y., Li, G., et al. Geothermal energy development by circulating $\mathrm{CO}_{2}$ in a U-shaped closed, loop geothermal system. Energy Conversion and Management, 2018, 174: 971-982.

Sun, Z. X., Zhang, X., Xu, Y., et al. Numerical simulation of the heat extraction in EGS with thermal-hydraulicmechanical coupling method based on discrete fractures model. Energy, 2017, 120: 20-33.

Wang, G., Song, X., Shi, Y., et al. Production performance of a novel open loop geothermal system in a horizontal well. Energy Conversion and Management, 2020, 206: 112478.

Wang, K., Wu, X. Downhole thermoelectric generation in unconventional horizontal wells. Fuel, 2019, 254: 115530.

Zaigham, N. A., Nayyar, Z. A. Renewable hot dry rock geothermal energy source and its potential in Pakistan. Renewable and Sustainable Energy Reviews, 2010, 14(3): 1124-1129.

Zeng, Y. C., Su, Z., Wu, N. Y. Numerical simulation of heat production potential from hot dry rock by water circulating through two horizontal wells at Desert Peak geothermal field. Energy, 2013, 56: 92-107.

Zhao, Y., Feng, Z., Feng, Z., et al. THM (Thermo-hydromechanical) coupled mathematical model of fractured media and numerical simulation of a 3D enhanced geothermal system at $573 \mathrm{~K}$ and buried depth 60007000 M. Energy, 2015, 82: 193-205.

Zhou, Z., Jin, Y., Zeng, Y., et al. Investigation on fracture creation in hot dry rock geothermal formations of China during hydraulic fracturing. Renewable Energy, 2020, 153: 301-313. 